\title{
Happy@Work: protocol for a web-based randomized controlled trial to improve mental well-being among an Asian working population
}

\author{
Qi Yuan, Su Liu*, Szehang Tang and Dexing Zhang
}

\begin{abstract}
Background: Mental health issues pose a serious concern in the workplace for the huge productivity loss and financial burden associated with it. Unlike the traditional 'fixing-what-is-wrong' approach, positive psychology offers a less-stigmatized way to promote mental health. Psychological capital, a concept originated from positive psychology, has been proven effective in improving mental well-being and work performance. However, little evidence exists for its implementation among Asian working population or its cost-benefit for organizations adopting such promotion strategy. The current study is designed to assess the protective effects of a web-based psychology capital intervention among Hong Kong working population on individuals' mental health and work performance, as well as organizations' return-on-investment.

Methods/Design: A two-arm randomized controlled trial design will be adopted. Eligible working adults will be randomly allocated to either the intervention group or the waiting-list control group, with 177 participants in each $\mathrm{arm}$. The intervention, which consists of four web-based training sessions, each targeting one of the psychological capital components (hope, efficacy, optimism and resilience), will be implemented over a 4-week period. On-line surveys will assess the participants in each group at baseline, intervention completion, 1 and 3 months after the completion. The primary outcome is individuals' psychological capital level; secondary outcomes include individuals' well-being, depressive symptoms, work engagement and productivity. Return-on-investment will be calculated from the employers' perspective based on productivity gain, savings in medical expenditure, as well as operation and time costs. Analysis will follow the intention-to-treat principle.

Discussion: This is the first experimental study that explores the applicability of psychological capital development among Asian population. Through investigating changes in individuals' work productivity from absenteeism and presenteeism, this will be one of the few studies that quantify productivity gains from any type of mental health promotion. By demonstrating effectiveness in improving mental well-being and a positive return-on-investment rate, the study may help convince more uptake of similar positive psychology interventions at workplace in Asia and elsewhere.
\end{abstract}

Trail Registration: Number (assigned by Centre for Clinical Trials, Clinical Trials Registry, The Chinese University of Hong Kong): CUHK_CCT00396. Registration Date: 2014/02/13

Keywords: Mental health, Promotion, Positive psychology, Psychological capital, Return-on-investment, Working population, Hong Kong

\footnotetext{
* Correspondence: sliu@cuhk.edu.hk

JC School of Public Health and Primary Care, the Chinese University of Hong Kong, Shatin, Hong Kong SAR
}

\section{Biomed Central}

(c) 2014 Yuan et al.; licensee BioMed Central Ltd. This is an Open Access article distributed under the terms of the Creative Commons Attribution License (http://creativecommons.org/licenses/by/4.0), which permits unrestricted use, distribution, and reproduction in any medium, provided the original work is properly credited. The Creative Commons Public Domain Dedication waiver (http://creativecommons.org/publicdomain/zero/1.0/) applies to the data made available in this article unless otherwise stated. 


\section{Background}

Accounting for $5.45 \%$ of global disease burden in 2010, mental disorders have become a significant public health threat and are expected to cause even heavier burden to society in the coming years [1]. The economic loss associated with mental disorders is particularly striking among the working-age adults, as these conditions affect individuals' work performance, short-term disability, absenteeism, as well as turnover rate [2,3]. These, in turn, affect productivity and business performance. Estimates indicate that mental disorders had cost the business sector $\$ 50.7$ billion in the United States [4], \$14.4 billion in Canada [5] and $\$ 14.8$ billion in Australia [6] annually. Globally, the cumulative loss of economic output due to mental disorders is estimated to reach $\$ 16$ trillion in the next 20 years, or $25 \%$ of world Gross Domestic Product (GDP) in 2010 [7]. Since 2000, the World Health Organization (WHO) has pointed out that there is a need among employers to recognize mental health issues as a legitimate workplace concern [8].

However, mental disorders are usually associated with stigma and discrimination. Compared with treating the diseases themselves, coping with the stigma is often reported to be more difficult [9]. In the workplace where individuals are supposed to be productive, such stigma can be worse. Employees with depression or other mental disorders may avoid assistance and effective treatment, as a result [10]. Facing this challenge, promoters of workplace mental health have been searching for an alternative more positive approach than the traditional "fixing-what-is-wrong" intervention. The rationale for positive psychology interventions (PPIs) is to nurture the strengths or positive traits of individuals, thereby buffer the negative effects of stressors and improve their mental health status. It represents a far-less-stigmatized approach, therefore, has more potential to be effective as a general strategy for prevention, particularly in the workplace. Indeed, previous studies among both general population [11] and working population [12,13] demonstrated that PPIs are effective in promoting subjective well-being, with an effect size of 0.3 [14].

Based on the principles of positive psychology and organization behavior, Luthans and colleagues further developed the concept of Psychological Capital (PsyCap) [15]. It includes four personal strengths (namely, hope, efficacy, optimism and resilience), which are theoretical based, state-like (measurable and developable) and manageable for work performance improvements [15]. The potential role of PsyCap in promoting mental health in the workplace could be better illustrated through the Conservation of Resources (COR) Theory. Under the COR theory, people seek to obtain, retain, and protect resources; and stress occurs when there is a net loss of resources, the threat of loss, or a lack of resource gain following the investment [16]. At the same time, resource gains could buffer the negative effects of resource loss and create more opportunity for further gains [17].

For employees, workplace adversities are natural circumstances for resource loss, which could then lead to stress; while PsyCap, just like human and social capital, can be considered as another resource that is developable and accumulative. Gaining such resource therefore will have a potential protective effect against future resource loss. Evidence could be found in a cross-sectional study, which reported higher PsyCap level associated with higher psychological well-being over time [18]. This is further confirmed by one meta-analysis, in which a significant positive relationship between PsyCap and desirable employee attitudes, behaviors and performance was reported [19]. However, almost all the studies that explore the relationship between PsyCap and mental health outcomes by now were observational and crosssectional in nature. Empirical evidence based on more rigorously controlled experimental study is in much need.

\section{Return-on-investment from employers' perspective}

Given the large stake that employers have in avoiding the cost associated with mental disorders among staff and the potential benefit the improved productivity could bring, it is not surprising that employers, particularly large companies have started investing in programs promoting mental health at workplace $[20,21]$. The question is whether these programs would have positive returnon-investment (ROI). Only upon proving positive ROI and making the business case can more employers be convinced to do more on this important issue, which could in turn have bigger public health impact. There has been only one previous study that estimated a ROI of 2.7 for PsyCap development [22]. The study, however, was based on a small sample from a single company, without a direct measure of improvement in work performance. The gap left in the literature is yet to be filled.

\section{Mental health among working population in Hong Kong}

Although cross-cultural differences in expressing, interpreting and treating symptoms of mental disorders have long been recognized, studies of psychological interventions have predominantly focused among Caucasians in America and Europe [23]. With more and more Asian countries recognizing the rising burden associated with mental disorders [24], there is an increasing need of culturally competent interventions and studies evaluating their effectiveness in this part of the world. Such need is particularly strong in Hong Kong, where an estimated 14.5- 24.6 percent of citizens have a mental disorder [25]. Specifically for working population, the $2008 \mathrm{Hong}$ Kong Work and Life Balance Survey showed that the 
average work week is about 49.6 hours, 25 percent more than the global standard; more than 80 percent of people said that they suffered stress, and $28 \%$ reported depression [26]. Given the increasing burden of mental disorders, the WHO suggested that priority should be put on prevention and promotion [27]. However, in Hong Kong, most of the resources remain in treatment, and only a disproportionately small amount is placed on prevention [28].

Like many Asian societies, Confucianism, with collectivism as one of its key traditions [29], is rooted in Hong Kong [30]. Although several experimental studies [31-33] demonstrated that PsyCap was developable, none was targeting Asian population. How would a PsyCap intervention work in promoting mental well-being and producing positive ROI among an Asian population that emphasizes collectivism rather than individualism, such as the working population in Hong Kong? This is the key research question we try to answer with this research protocol.

\section{Aims of the research}

Our study aims to demonstrate the effectiveness and cost-effectiveness of a psychological capital development intervention (named "Happy@Work") for improving the mental well-being among working population in Hong Kong. Through designing the intervention in an on-line platform customized for local business and social environment, we will investigate the processes by which individuals from the eastern culture may adhere to the treatment and develop PsyCap. Our research will also fill some gaps in the current literature by testing hypotheses raised yet lacking evidence, for example, can the intervention benefit depressed individuals more than nondepressed ones? In addition, we will calculate the ROI of this intervention, intended for the business sector to take further actions.

\section{Methods/Design Study design}

This study is designed as a two-arm randomized control trial. Upon visiting the intervention website, individuals will complete an initial screening to determine the eligibility. Eligible participants will continue the registration process and the baseline assessment, followed by an automatic randomization process that assigns the eligible participants into one of two groups. The intervention group will receive a 4-week access to Happy@Work trainings that develop each of the four PsyCap components. Measurements are scheduled at baseline, directly after the 4-week PsyCap trainings, and at 1 and 3 months follow up. The control group will be on the waiting list for 4 months before they can access the training materials. Figure 1 shows the flow of the study design.
This study is registered in the Centre for Clinical Trials, Clinical Trials Registry, the Chinese University of Hong Kong (CUHK_CCT00396). The study protocol, informed consent procedure and survey instruments have been approved by the Joint Chinese University of Hong Kong New Territories East Cluster (CUHK-NTEC) Clinical Research Ethics Committee (CREC), under the reference number CRE-2014.001.

\section{Inclusion and exclusion criteria}

Participants will be included if they: (1) are above 18 years old; (2) have a full-time job for at least 1 month (to ensure that we can compare work productivity before and after the intervention); (3) have access to the internet and (4) have sufficient knowledge in using computers and understanding traditional Chinese (i.e., the language the intervention program is developed in).

In order to monetize the work productivity changes, we need information such as monthly salary for participants. In this case, individuals who do not receive any monthly salary from current jobs (e.g. voluntary workers) will be excluded. Because of the ethical consideration and potential contaminations, individuals who are currently receiving professional mental health treatment or taking any psychotropic medication will be excluded as well.

\section{Sample size}

Based on the existing evidence from PPIs, we expect to find a standard effect size of 0.3 or larger comparing the intervention group with the control group [14]. To achieve a statistical power of $80 \%$, given a two-sided alpha of 0.05 , we need at least 177 participants in each condition, i.e. a sample size of 354 or more.

\section{Recruitment of participants}

Since the intervention is designed to cater needs among local general working population, recruitment of participants is open to the public. Advertisement about the Happy@Work program is put up in relevant local magazines, websites, and other public space. Anyone who meets the eligibility criteria is welcome to participate. Furthermore, to maximize the recruitment efforts and to increase awareness among employers, we will also approach them directly, targeting consent from Human Resources managers to encourage staff to participate. More specifically, we have strategically teamed up with the Employers' Federation of Hong Kong in the beginning, so that the Federation can recruit participants from its member organizations (mostly companies of large sizes). We will also contact small-medium enterprises associations and conduct workshops for specific companies through professional networks to further promote the program. During recruitment, we will highlight the potential benefits of the program, appealing to 


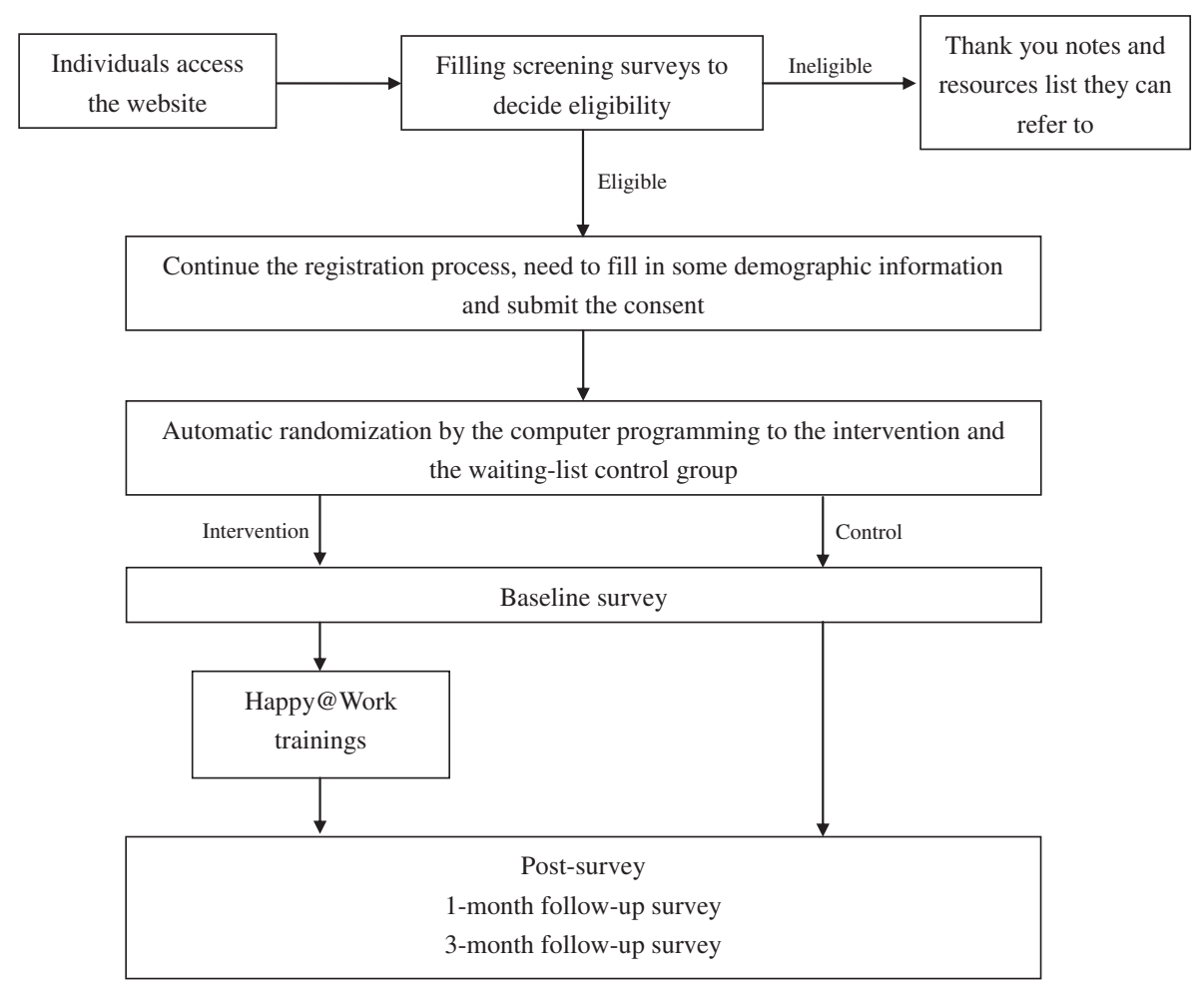

Figure 1 After the screening, eligible participants will continue the registration process, followed by the baseline assessment. The automatic randomization afterwards will then randomly allocate them into the intervention and the waiting-list control group. The intervention group participants will receive the Happy@Work trainings; while the control group will be on the waiting-list for 4 months. Both groups need to finish post-intervention, 1-month and 3-month follow-up surveys.

different audiences. For employers, we emphasize its effect on increasing morale and productivity, while reducing turn-over and medical cost; for individuals, we highlight the benefit of improving well-being and career development, while managing stress.

High dropout rate is a challenge often faced by webbased studies. We use several strategies and incentives to mitigate this problem: 1) Email reminders will be sent out to remind participants at different stages (e.g. upon availability of each training session) to adhere to the process and complete all trainings and assessments on schedule; 2) Conditioning on finishing all the assessments, an electronic certificate for participation will be awarded to participants who have successfully completed all four training sessions; 3 ) a HK\$50 cash coupon will be offered to the first 500 participants (in either control or intervention group) who complete all the assessments.

\section{Description of intervention Intervention content}

Happy@Work is an individualized self-learning webbased program. The content of the intervention is designed based on a thorough literature review on PysCap [22,32-41]. It includes four training sessions, each targeting one of the four PsyCap components (Table 1): 1) hope, where a goal-setting training will be provided, mainly teaching individuals how to set up SMART (Specific, Measureable, Achievable, Relevant and Timebound) goals [31-33]; 2) efficacy, an expressive writing training, which requires individuals to write about their personal feelings on their own work, past mastery experiences on work-related issues, etc. [35,42]; 3) optimism, which teaches individuals the $\mathrm{ABCDE}$ model (Adversity, Belief, Consequences, Disputation and Energization) of "learned optimism" [41]; and 4) resilience, where the risk management and resource leverage practice skills will be trained [31-33].

In order to adapt the intervention to the local business and culture environment, we held a small focus group talking to four human resources managers of local companies ( 3 from large firms in banking, communication, and professional service, respectively and 1 from smallmedium enterprises). We asked the managers to describe the key issues staff faces in the day-to-day operations, the common sources of stress or challenges, and what a "star" employee would be like. Based on the discussion, we developed cases for typical types of adversity local workers are expected to experience, thus demonstrate how each of the PsyCap component can be utilized. 
Table 1 Content of the intervention program

\begin{tabular}{|c|c|}
\hline Components & Proposed training \\
\hline Hope & Goal setting (i.e. 1. Choosing of a personal goal; 2. Creating sub-goals; 3. Pathways generation; 4. Obstacle planning) \\
\hline Efficacy & $\begin{array}{l}\text { Expressive writing (i.e. adapted from existing guideline, basically requires individuals to write about their personal feelings on their } \\
\text { own work; past mastery experiences on work-related issues; vicarious learning experiences; as well as the verbal persuasion } \\
\text { experiences) }\end{array}$ \\
\hline Optimism & $\begin{array}{l}\text { Learned optimism (i.e. ABCDE model: 1) A stands for adversity; 2) B for the beliefs one automatically has when it occurs; } 3 \text { ) C for the } \\
\text { usual consequences of the belief; 4) D for the disputation of individuals' routine belief; 5) E for the energization that occurs when } \\
\text { individuals dispute the belief) }\end{array}$ \\
\hline Resilience & $\begin{array}{l}\text { Risk management \& Resource leverage practice (i.e. evaluating the risk for an adversity; practicing using different perspective to view } \\
\text { it; planning strategies to control it; figuring out resources available and methods of getting more helpful resources; utilizing the } \\
\text { resources to deal with the adversity) }\end{array}$ \\
\hline
\end{tabular}

\section{Intervention delivery}

A web-based format will be adopted to deliver the whole intervention and conduct assessment. Compared with traditional approaches, such as face-to-face counseling, a web-based approach has several advantages: 1) relatively cheaper; 2) once developed, it may be sustained and maintained with little cost to serve more people; 3 ) more flexible for individuals, in the sense that they can choose wherever or whenever to access the program; and 4) the web-based data collection would obviate data entry by the researcher (and associated human error). In terms of efficacy, one meta-analysis found that web-based instruction has similar effects as classroom instruction on teaching both declarative knowledge and procedural knowledge [43]. As for data quality, previous studies have shown that data collected via internet are just as diverse as data collected through traditional methods, and participants in web-based studies would treat the study the same or to provide accurate information as participants in traditional samples [44].

We worked with a web design vendor to combine the skill trainings and the localized cases through narrative technology such as flash animation. Each session is delivered in a pseudo-classroom setting, with the same trainer (an animated character) mainly providing the knowledge and guiding participants through the trainings. In addition to the participant, another animated character (different in each session) will act as the classmate who will present the specific case developed above as his or her own work challenge, and together with the participant, try to apply the skill learned. By providing such a role model for each session, we aimed to improve the learning efficiency of participants. Once participants start a session, the flash animation will automatically play by itself, with stops built in for either a "whiteboard" function or "check-point" questions. The "whiteboard" function is designed to display key knowledge/ training points in a more self-controlled pace (with move-back or move-forward buttons); while the "checkpoint" questions (multiple-choice or brief answer questions) are built in as "breaks" during the class, which also allow participants to be tested on knowledge gained. Generally, it takes 15-30 minutes to complete each session. To better motivate participants, "happy coins" (virtual money value) are rewarded when they correctly answer the "check-point" questions or finish "homework", the latter consists of post-session exercises participants can access after completing the training to reinforce skills learned.

Four training sessions are released one by one on a weekly base in a preset order (i.e. hope - efficacy - optimism - resilience), so that following each session individuals could have a week to practice the learned skills. A timer linked to each participant's password-protected account is used to control individual progress. Upon completion of baseline assessment, the timer will start. Participants have up to a week to complete each training and practice the skills learned through accessing "homework", and they can always revisit the previous sessions. Automatic email reminders will be sent out two days after a training session is available but not yet accessed. This is scheduled to help participants better follow through the whole intervention, which will take four weeks after baseline assessment.

\section{Control group}

A waiting-list control condition will be employed. After the baseline assessment, the control group will receive a note informing them that they need to wait for four months before accessing the training materials. During the four-month waiting period, we will send email reminders to remind them to finish the post/follow-up surveys. As an incentive, the control group is also eligible to receive cash coupons upon completing all assessments.

\section{Outcome assessment}

The primary outcome is the level of psychological capital. The secondary outcomes include well-being, depressive symptoms, work engagement and economic cost-benefit (as measured by work productivity, medical expenditure and time cost for using the website). All these measures 
are self-reported, and will be collected through the Happy@Work website. Assessments will be made at the baseline, immediately after individuals finish the 4-week trainings, and at 1 and 3 months follow-up after the completion. All the measurements, except specified, will be assessed in both control and intervention groups.

\section{Mental health status measures}

The level of psychological capital will be assessed by the 24-item psychological capital questionnaire (PsyCap-24) [15]. It includes 6 items for each of its 4 components (hope, efficacy, optimism and resilience). Participants will be asked to rate the items using a 6-point scale, ranging from 1 (strongly disagree) to 6 (strongly agree). A higher score indicates higher PsyCap level. The PsyCap24 has already been translated into Chinese and adapted in a previous Hong Kong study, showing excellent internal reliability (Cronbach's alpha equals to 0.92) [45].

Well-being will be measured by the Warrick-Edinburgh Mental Well-being Scale (WEMWS) [46] and the Satisfaction with Life Scale (SWLS) [47], both are already available in Chinese. The WEMWS is a 14-item self-rating scale with item scores ranging from 1 to 5 . The SWLS only has 5 items, where participants are asked to rate on a 7-point Likert scale, ranging from 1 (strongly disagree) to 7 (strongly agree).

Depressive symptoms will be measured by Centre for Epidemiologic Studies Depression Scale (CES-D) $[48,49]$. The CES-D includes 20 items, using a 4-point Likert scale (ranging from 0 to 3 ) to rate individuals' depressive symptoms. It has been validated in Hong Kong before [50]. Score ranges from $0-60$, with higher scores indicating more severe depression. A score of 16 to 26 for CES-D is considered as potential mild depression, and 27 or above as major depression.

\section{Work engagement and $\mathrm{ROI}$ related measures}

The Utrecht Work Engagement Scale - shorten version (UWES) [51] will be used to measure engagement. It is a 9 -item self-rating scale with item scores from 0 to 6 . It has an excellent internal consistency (e.g. Cronbach's alpha varied between 0.85 to 0.92 across different samples from 10 countries [52]).

Work productivity changes will be measured by the WHO's Health and Performance at Work Questionnaire - short form (HPQ) [53], which obtains information on individuals' past 4 weeks productivity through assessing both absenteeism and presenteeism. It is currently unavailable in traditional Chinese. A standard 'translation and back-translation' process was adopted to translate it into traditional Chinese [54]. We pre-tested the Chinese version before making further improvement.

The other two components for calculating the ROI besides work productivity are medical costs and time costs.
To obtain these two measures, participants in both control and intervention groups will be asked to report the past-month medical expenditures and the share paid by their employers (if any); while the intervention group alone will also report time they spend on the entire trainings.

\section{Demographics and other variables}

The demographic information will be collected during the registration. In the post-intervention survey, participants of the intervention group will be asked to report their satisfaction level towards our program; a manipulation check question will also be employed to explore the potential moderation effect between individuals' selfrated devotion level and other individual-level outcomes. The control group participants, on the other hand, will be asked to report whether they have been exposed to any educational information related to mental health or psychology during the past four weeks.

\section{Treatment adherence and user experience}

Because this is the first on-line positive psychology intervention conducted in Hong Kong and among the few in Asia, we will also evaluate the process to better understand user experience and to test the extent to which treatment is adhered and intervention is successfully implemented. In addition to the self-rated devotion level, we will collect timing and progress information (built in behind the scene as part of the system record), while participants $\log$ in every time and move along each training session, answer "check-point questions" and complete "homework". The amount of "happy coins" itself could serve as another indicator of participants' level of commitment to the learning experience. As part of the post-intervention assessment, we ask participants to leave open-ended comments. For those who quit the program, we plan to conduct some follow-up interviews to better understand their experience and the reasons behind the drop-out.

\section{Data analysis}

Results will be reported according to the Consolidated Standards of Reporting Trials (CONSORT) statement regarding eHealth [55]. The primary data analysis will follow the intention-to-treat principle and compare the differences in the above outcome measures between the intervention group and the wait-list control group. Because of the potential dropout, missing data is expected. When appropriate, we will use the expectation-maximization (EM) method to impute missing data [56]. In addition, perprotocol analysis will also be conducted.

The two groups will first be described in terms of their baseline characteristics. The primary data analysis will compare the effectiveness of Happy@Work in the intervention 
group with the changes in the control group, based on the differences on PsyCap-24, WEMWS, SWLS, CES-D and UWES. Repeated measures of ANOVA will be used to check the multivariate main effects of intervention (compared with control) and time (pre, post, follow-up), as well as their interaction effect. A two-sided P value of 0.05 or less will be considered as significant. We will compute the standardized effect size (Cohen's d) as well. Moderator analysis will also be conducted to explore which sub-group/s would benefit more from the intervention, by regressing outcome variables on independent variables like age, gender, education and baseline CES-D scores. Work productivity change will be compared between these two groups as well. SPSS V.18 will be used for the data analysis.

To make the business case for similar type of interventions, return-on-investment of the program will be calculated from the employers' perspective using the following formula:

ROI $=($ Gain from investment - Cost of investment $) /$ Cost of the investment;

where, Gain from investment $=$ total monetized value of employees' work productivity gains + savings in employers' share of medical cost; and

Cost of investment $=$ Program designing and operation costs (assuming employers self-fund similar programs) + the monetized time cost (if employees use work time for the program training).

Self-reported monthly salary will be used to monetize the work productivity changes and time cost for each individual. All the afore-mentioned items will be the incremental value compared with the control group.

\section{Discussion}

\section{Strengths and limitations}

To the best of our knowledge, this is the first experimental study that explores the applicability of PsyCap development among Asian population; and it is also one of the few studies that measure improvement in depression and mental well-being as a result of PsyCap development. We will also examine differences in these outcomes between individuals with different level of depressive symptoms. Through the investigation of changes in individuals' work productivity from absenteeism and presenteeism, our study will be one of the few studies that quantify productivity gains and return-on-investment from any type of mental health promotion.

There are also several limitations that we need to mention. Compared with group based or individual based consultation, although web-based self-administrated interventions are usually cheaper, it might also be less effective. Meanwhile, since we will mainly use self-report method to collect data, this might cause recall bias. The ROI estimation will be less objective compared with those studies that choose one specific company and use the company records (e.g., medical claims, sick leave days) for such calculation. Another limitation would be the possible high dropout rate for this study, despite self-selection and other strategies to reduce it (e.g. email reminders and other incentives). Although studies have found that self-selected people enjoyed more obvious effects than non-self-selected individuals in PPIs [57], this also calls for caution against over-generalizing our results.

\section{Future implementation}

If through this study, we are able to prove the intervention not only effective in improving the mental wellbeing of working individuals, but also bringing positive return-on-investment for employers, further efforts to improve the program, or customize it for specific industry or company is anticipated. Our research partner, the Employers' Federation of Hong Kong would assist in this process and further funding may be sought. What's more, a network of public and private organizations interested in the workplace mental health issues is being developed, as a side product of our recruiting efforts. We will disseminate research findings to this network and more broadly to the public. As a result, more organizations (especially those with large number of employees working under stressful condition) may be willing to invest more in similar initiatives or customize Happy@Work to fit their own needs in the future.

\section{Abbreviations}

GDP: Gross domestic product; WHO: World health organization; PPIs: Positive psychology interventions; PysCap: Psychological capital; COR: Conservation of resource theory; ROI: Return-on-investment; PsyCap-24: The 24-item psychological capital questionnaire; WEMWS: Warrick-edinburgh mental well-being scale; SWLS: Satisfaction with life scale; CES-D: Centre for epidemiologic studies depression scale; UWES: The Utrecht work engagement scale - shorten version; HPQ: The WHO's Health and Performance at Work Questionnaire;

CONSORT: Consolidated standards of reporting trials; EM: Expectation-maximization.

\section{Competing interests}

The authors declare that they have no competing interests.

\section{Authors' contributions}

QY and SL conceived the study, and participated in its design. QY drafted the manuscript. SL is the principle investigator for this study and she revised the manuscript. SHT contributed to the design of the intervention program. DXZ contributed to the research protocol and the data analysis plan. All authors read and approved the final version of the manuscript.

\section{Acknowledgements}

We want to express our appreciation to Prof. Nicola Schutte from the University of New England for offering us the self-efficacy development guideline. We are also grateful to Prof. Carolyn Youssef, Prof. Wilmar Schaufeli, Ms Linda Bolier, Ms Richta ljntema, Ms Ulike Wild, Ms Catelijne Jolink, Prof Winton Au, Prof. Winnie Mak and Prof. Samuel Wong for their comments and suggestions during the designing phase for the intervention program. We also want to thank Ms. Jodi Koon from the Employer's Federation of Hong Kong for helping us recruiting the participants. This trial is funded by the Health Care and Promotion Fund, the Food and Health Bureau of the Hong Kong government 
Received: 13 June 2014 Accepted: 1 July 2014

Published: 4 July 2014

\section{References}

1. Whiteford HA, Degenhardt L, Rehm J, Baxter AJ, Ferrari AJ, Erskine HE, Charlson FJ, Norman RE, Flaxman AD, Johns N: Global burden of disease attributable to mental and substance use disorders: findings from the Global Burden of Disease Study 2010. Lancet 2013, 382(9904):1575-1586.

2. Goetzel RZ, Ozminkowski RJ, Sederer LI, Mark TL: The business case for quality mental health services: why employers should care about the mental health and well-being of their employees. J Occup Environ Med 2002, 44(4):320-330.

3. Palmer S, Dryden W: Stress management: Approaches and interventions. Br J Guid Couns 1994, 22(1):5-12.

4. Kessler R, Akiskal H, Ames M, Birnbaum H, Greenberg P, Jin R, Merikangas K, Simon G, Wang P: Prevalence and effects of mood disorders on work performance in a nationally representative sample of US workers. Am J Psychiatr 2006, 163(9):1561-1568.

5. Stephens T, Joubert N: The economic burden of mental health problems in Canada. Chronic Dis Can 2001, 22(1):18-23.

6. Econtech: The Cost of Workplace Stress in Australia. Australia: Econtech; 2008. 7. Bloom DE, Cafiero E, Jané-Llopis E, Abrahams-Gessel S, Bloom L, Fathima S, Feigl A, Gaziano T, Mowafi M, Pandya A: the global economic burden of noncommunicable diseases. Geneva: World Economic Forum. 2011. 2012.

8. Dependence S: Mental health and work: Impact, issues and good practices. 2000

9. Gabriel P: Mental Health in the Workplace: Situation Analyses, United States. Int Labour Organ 2000, 228. http://digitalcommons.ilr.cornell.edu/ cgi/viewcontent.cgi?article $=1229 \&$ context $=$ gladnetcollect.

10. Stuart H: Mental illness and employment discrimination. Curr Opin Psychiatry 2006, 19(5):522-526.

11. Seligman ME, Steen TA, Park N, Peterson C: Positive psychology progress: empirical validation of interventions. Am Psychol 2005, 60(5):410-421.

12. Chan D: Burnout and Life Satisfaction: Does Gratitude Intervention Make a Difference among Chinese School Teachers in Hong Kong? Educ Psychol 2011, 31(7):809-823.

13. Hartfiel N, Havenhand J, Khalsa SB, Clarke G, Krayer A: The effectiveness of yoga for the improvement of well-being and resilience to stress in the workplace. Scand J Work Environ Health 2011, 37(1):70-76.

14. Bolier L, Haverman M, Westerhof G, Riper H, Smit F, Bohlmeijer E: Positive psychology interventions: a meta-analysis of randomized controlled studies. BMC Public Health 2013, 13(1):1-20.

15. 15. Fred Luthans CMYaBJA: Psychological Capical: Developing the Human Competitive Edge. Oxford: University Press; 2007.

16. Hobfoll SE: Conservation of resources: A new attempt at conceptualizing stress. Am Psychol 1989, 44(3):513.

17. Hobfoll SE, Schumm JA: Conservation of resources theory. In Emerging theories in health promotion practice and research: Strategies for improving public health. San Francisco, CA: Jossey-Bass; 2002:285-312.

18. Avey JB, Luthans F, Smith RM, Palmer NF: Impact of positive psychological capital on employee well-being over time. J Occup Health Psychol 2010, 15(1):17-28

19. Avey JB, Reichard RJ, Luthans F, Mhatre KH: Meta-analysis of the impact of positive psychological capital on employee attitudes, behaviors, and performance. Hum Resour Dev Q 2011, 22(2):127-152.

20. Page KM, Vella-Brodrick DA: The working for wellness program: RCT of an employee well-being intervention. J Happiness Stud 2013, 14(3):1007-1031.

21. Henke RM, Goetzel RZ, McHugh J, Isaac F: Recent experience in health promotion at Johnson \& Johnson: lower health spending, strong return on investment. Health Aff 2011, 30(3):490-499.

22. Fred Luthans JBA, Avolio BJ, Norman SM, Combs GM: Psychological Capital development: toward a micro-intervention. J Organ Behav 2006, 27:387-393.

23. Chang SM, Hahm B-J, Lee J-Y, Shin MS, Jeon HJ, Hong J-P, Lee HB, Lee D-W, Cho MJ: Cross-national difference in the prevalence of depression caused by the diagnostic threshold. J Affect Disord 2008, 106(1):159-167.

24. Yeh LL LY, Yang MC, Lau SK, Hwu HG: The economic cost of the severely mentally ill patients. Chin J Ment Health 1999, 1:15.

25. Hospital Authority: Hospital Authority mental health service plan for adults 2010-2015. Hong Kong: Hospital Authority; 2009.

26. Welford R: Work life balance in Hong Kong_survey results. In. Hong Kong: CST Asia \& The University of Hong Kong; 2008.
27. World Health Organization: Prevention and promotion in mental health. Geneva: World Health Organization; 2002.

28. Ip Y: Mental health promotion in Hong Kong. Hong Kong J Psychiatry 2002 12(3):2-4.

29. Kramer EJ, Kwong K, Lee E, Chung H: Cultural factors influencing the mental health of Asian Americans. West J Med 2002, 176(4):227.

30. TONG HK, 湯浩堅, LEUNG WH, 梁慧霞: How Confucianism affects Hong Kong educators' views on modern Chinese language education. 2007.

31. Luthans F, Avey JB, Avolio BJ, Peterson SJ: The development and resulting performance impact of positive psychological capital. Hum Resour Dev Q 2010, 21(1):41-67.

32. Luthans F, Youssef CM, Avolio BJ: Psychological capital: Developing the human competitive edge. Oxford: Oxford University Press; 2006.

33. Luthans F, Avey JB, Patera JL: Experimental analysis of a web-based training intervention to develop positive psychological capital. Acad Manag Learn Educ 2008, 7(2):209-221.

34. Cheavens JS, Feldman DB, Gum A, Michael ST, Snyder C: Hope therapy in a community sample: A pilot investigation. Soc Indic Res 2006, 77(1):61-78.

35. Kirk BA, Schutte NS, Hine DW: The Effect of an Expressive-Writing Intervention for Employees on Emotional Self-Efficacy, Emotional Intelligence, Affect, and Workplace Incivility. J App/ Soc Psychol 2011, 41(1):179-195.

36. Liossis PL, Shochet IM, Millear PM, Biggs H: The Promoting Adult Resilience (PAR) Program: The Effectiveness of the Second, Shorter Pilot of a Workplace Prevention Program. Behav Chang 2009, 26(02):97-112.

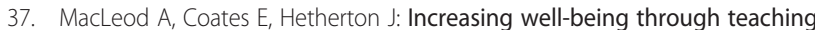
goal-setting and planning skills: results of a brief intervention. $J$ Happiness Stud 2008, 9(2):185-196.

38. Peters ML, Meevissen YMC, Hanssen MM: Specificity of the Best Possible Self intervention for increasing optimism: Comparison with a gratitude intervention. terapia psicolÓgica 2013, 31(1):8

39. Shimazu A, Kawakami N, Irimajiri H, Sakamoto M, Amano S: Effects of web-based psychoeducation on self-efficacy, problem solving behavior, stress responses and job satisfaction among workers: a controlled clinical trial. J Occup Health 2005, 47(5):405-413.

40. Vuori J, Toppinen-Tanner S, Mutanen P: Effects of resource-building group intervention on career management and mental health in work organizations: randomized controlled field trial. J Appl Psychol 2012, 97(2):273-286

41. Seligman ME: Learned optimism: How to change your mind and your life. Mehrad Ahari: Random House LLC; 2011.

42. Fitzgerald S, Schutte NS: Increasing transformational leadership through enhancing self-efficacy. J Manag Dev 2010, 29(5):495-505.

43. Sitzmann T, Kraiger $K$, Stewart D, Wisher R: The comparative effectiveness of web-based and classroom instruction: A meta-analysis. Pers Psychol 2006, 59(3):623-664.

44. Gosling SD, Vazire S, Srivastava S, John OP: Should we trust web-based studies? A comparative analysis of six preconceptions about internet questionnaires. Am Psychol 2004, 59(2):93

45. Lok LC: A study of positive emotions and turnover intentions aomng Hong Kong police officers: the mediating role of Psychological Capital and work well-being. MPhil thesis. Hong Kong: Lingnan University; 2011.

46. Taggart F, Friede T, Weich S, Clarke A, Johnson M, Stewart-Brown S: Cross cultural evaluation of the Warwick-Edinburgh Mental Well-being Scale (WEMWBS) -a mixed methods study. Health Qual Life Outcomes 2013, 11:27.

47. Diener E, Emmons RA, Larsen RJ, Griffin S: The Satisfaction With Life Scale. J Pers Assess 1985, 49(1):71-75.

48. Radloff LS: The CES-D Scale. Appl Psychol Meas 1977, 1(3):385-401.

49. Wong SH J, Lam TH: Central and Western District Adolescent Health Survey: Report of the Cross-sectional Survey. In Hong Kong: Department of Community Medicine, University of Hong Kong. 2004

50. Cheung CK, Bagley C: Validating an American scale in Hong Kong: the Center for Epidemiological Studies Depression Scale (CES-D). J Psychol 1998, 132(2):169-186.

51. Wilmar Schaufeli AB: Utrecht Work Engagement Scale - preliminary manual. Netherlands: Occupational Health Psychology Unit, Utrecht University; 2003.

52. Schaufeli WB, Bakker AB, Salanova M: The measurement of work engagement with a short questionnaire a cross-national study. EduC Psychol Meas 2006, 66(4):701-716.

53. Kessler RC, Barber C, Beck A, Berglund P, Cleary PD, McKenas D, Pronk N, Simon G, Stang P, Ustun TB: The world health organization health and work performance questionnaire (HPQ). J Occup Environ Med 2003, 45(2):156-174. 
54. Brislin RW: Back-translation for cross-cultural research. $J$ Cross-Cult Psychol 1970, 1(3):185-216

55. Eysenbach G, Group C-E: CONSORT-EHEALTH: improving and standardizing evaluation reports of Web-based and mobile health interventions. J Med Internet Res 2011, 13:4.

56. Do CB, Batzoglou S: What is the expectation maximization algorithm? Nat Biotechnol 2008, 26(8):897-900.

57. Sin NL, Lyubomirsky S: Enhancing well-being and alleviating depressive symptoms with positive psychology interventions: a practice-friendly meta-analysis. J Clin Psychol 2009, 65(5):467-487.

doi:10.1186/1471-2458-14-685

Cite this article as: Yuan et al:: Happy@Work: protocol for a web-based randomized controlled trial to improve mental well-being among an Asian working population. BMC Public Health 2014 14:685.

\section{Submit your next manuscript to BioMed Central and take full advantage of:}

- Convenient online submission

- Thorough peer review

- No space constraints or color figure charges

- Immediate publication on acceptance

- Inclusion in PubMed, CAS, Scopus and Google Scholar

- Research which is freely available for redistribution 